\title{
A semi-empirical method for predicting GOC in oil reservoirs with limited PVT dataset
}

\author{
Oluchukwu M. Okoh ${ }^{1} \cdot$ Kazeem A. Lawal ${ }^{2}$. Asekhame U. Yadua ${ }^{1} \cdot$ Mathilda I. Ovuru ${ }^{2} \cdot$ Stella I. Eyitayo ${ }^{2}$. \\ Saka Matemilola ${ }^{2}$
}

Received: 20 April 2020 / Accepted: 16 June 2020 / Published online: 26 June 2020

(c) Springer Nature Switzerland AG 2020

\begin{abstract}
Depending on the type, quality and quantity of available data, different methods exist to determine the hydrocarbonhydrocarbon contacts in reservoirs. These methods are either direct or indirect. While the direct method involves consciously drilling a well to penetrate potential fluid contacts, the indirect methods include pressure measurements across at least two different fluid types, and/or, the acquisition and subsequent characterization of downhole fluid samples. Recognizing that most petroleum reservoirs are compositionally graded to varying degrees, compositional grading simulation (CGS) is an inexpensive indirect method of evaluating potential gas-oil contact (GOC) in petroleum reservoirs. However, this typically requires detailed pressure-volume-temperature (PVT) data of the hydrocarbon fluids. But, in many cases, PVT data may be limited. To address the challenges in such cases, this paper proposes a new predictive model and practical workflow, hence extending the applicability of CGS. Employing several PVT datasets and rigorous CGS for known black and volatile oil reservoirs, a new semiempirical function is developed for estimating saturation pressure gradient from gas oil ratio (GOR), which is a readily measurable fluid property. Complementing this function, is the identification of a robust empirical model to predict saturation pressure. The associated workflow provides a systematic integration of the predictive saturation gradient and saturation pressure models to estimate the degree of undersaturation, and hence, potential GOC depth in a reservoir characterized by limited PVT dataset. For validation tests, some cases of saturated and undersaturated reservoirs in the Niger Delta are presented. The results confirm the applicability of the new method in the Niger Delta and elsewhere.
\end{abstract}

Keywords Compositional grading $\cdot$ Compositional grading simulations $\cdot$ Gas-oil contact $\cdot$ Saturation pressure $\cdot$ Oil reservoirs

\section{List of symbols}

A Absolute value of saturation pressure gradient (psi/ft)

$P_{\mathrm{bs}} \quad$ Saturation (bubble-point) pressure at sample depth (psia)

$P_{s} \quad$ Reservoir pressure at sample depth (psia)

$R_{\mathrm{si}} \quad$ Initial solution GOR (scf/stb)

$T \quad$ Reservoir temperature $\left({ }^{\circ} \mathrm{F}\right)$

$\mathrm{z}_{\mathrm{GOC}} \mathrm{GOC}$ depth (ft) $z_{\mathrm{s}} \quad$ Sample depth (ft)

$\gamma \quad$ Oil pressure gradient (psi/ft)

$\gamma_{\text {API }} \quad$ Stock-tank oil gravity $\left({ }^{0} \mathrm{API}\right)$

$\gamma_{\mathrm{g}} \quad$ Gas specific gravity (air $=1$ ) (dimensionless)

$\gamma_{\mathrm{o}} \quad$ Oil specific gravity (water $\left.=1\right)$ (dimensionless)

Oluchukwu M. Okoh, oluchukwu.okoh@nnpcgroup.com; Kazeem A. Lawal, kazeem.lawal@first-epdc.com; Asekhame U. Yadua, asekhame.yadua@nnpcgroup.com; Mathilda I. Ovuru, mathilda.ovuru@first-epdc.com; Stella I. Eyitayo, stella.eyitayo@first-epdc.com; Saka Matemilola, saka.matemilola@first-epdc.com | ${ }^{1}$ Nigerian Petroleum Development Company (NPDC), Benin, Edo, Nigeria. ${ }^{2}$ FIRST Exploration \& Petroleum Development Company (FIRST E\&P), Lagos, Nigeria. 


\section{Introduction}

A proper definition of fluid contacts is crucial for the characterization and exploitation of petroleum reservoirs. However, uncertainties in gas-oil contact (GOC) are not uncommon in oil and gas fields (Fig. 1 ). These uncertainties put reservoir developments and the associated investments at risk. To mitigate these risks in development planning and field management, it is imperative to reduce GOC uncertainties to a fail-safe status.

In practice, there are two broad methods of reducing GOC uncertainties. These are direct and indirect methods. Direct methods would include deliberately drilling a well to penetrate prospective fluid contacts in the reservoir, and acquiring relevant data such as petrophysical logs and pressure (Fig. 1). However, the execution of this method comes at significant financial costs, while increasing the health, safety and environmental (HSE) exposures of a project. In addition, the direct methods require that at least two fluids must be encountered before reaching conclusion on the depth of fluid contacts.

Concerned with the discouraging cost and HSE performances often associated with the direct methods, a few indirect methods are available to reduce GOC uncertainties. These indirect methods include inferences from (1) high-resolution seismic; (2) pressure-transient analysis (PTA); and (3) pressure-volume-temperature (PVT) analysis [1].

Although the interpretations are typically influenced by the quality of the seismic dataset, high-resolution seismic may yield good interpretation of a possible gas cap. However, in the absence of proper calibration, the flat spot seen on seismic may denote an oil-water contact (OWC), a GOC, or a gas-water contact (GWC). Due to a potential non-unique interpretation of flat spots, the definition of the fluid contact may not always be conclusive.

The deduction of a possible gas cap from PTA is predicated on appreciable rock and fluid property contrasts. These contrasts may yield non-unique signatures that can potentially be linked to any feature, either rock or fluid behavior. The non-uniqueness of resulting signatures, poses yet another challenge to a conclusive interpretation of fluid contacts form the indirect method of PTA.

GOC inference from PVT analysis exploits the principle of compositional grading. Specifically, compositional grading characterizes the change in composition of a fluid with depth. A plethora of papers have consistently shown that GOC is a consequence of thermodynamics [2-6]. Where PVT datasets are available, several case studies have been used to demonstrate that this technique is a relatively cheap and simple option for estimating potential GOC, yet with minimal HSE exposure [3].

The traditional application of the PVT method for estimating $\mathrm{GOC}$ requires an extensive dataset from detailed laboratory experiments conducted on a representative hydrocarbon sample [1, 3-5]. For credible analysis, subsurface fluid samples are generally preferred. However, in some cases, such samples may either not be available, or the required PVT dataset may be limited. Examples of such cases include insufficient fluid samples, financial constraints and operational challenges that preclude sample acquisition.

The phenomenon of varying composition across depths has been investigated over the years, turning out many influential publications in its trail. While Schulte explained the variations of composition with depth in a hydrocarbon column [6], Montel and Gouel presented methods of predicting fluid compositional grading under gravity effects only [7].

By incorporating the effects of gravity and thermal diffusion, Belery and da Silva as well as Whitson and Belery
Fig. 1 A schematic showing uncertainties in hydrocarbon type and potential GOC up-dip of an existing well in a known oil-bearing reservoir

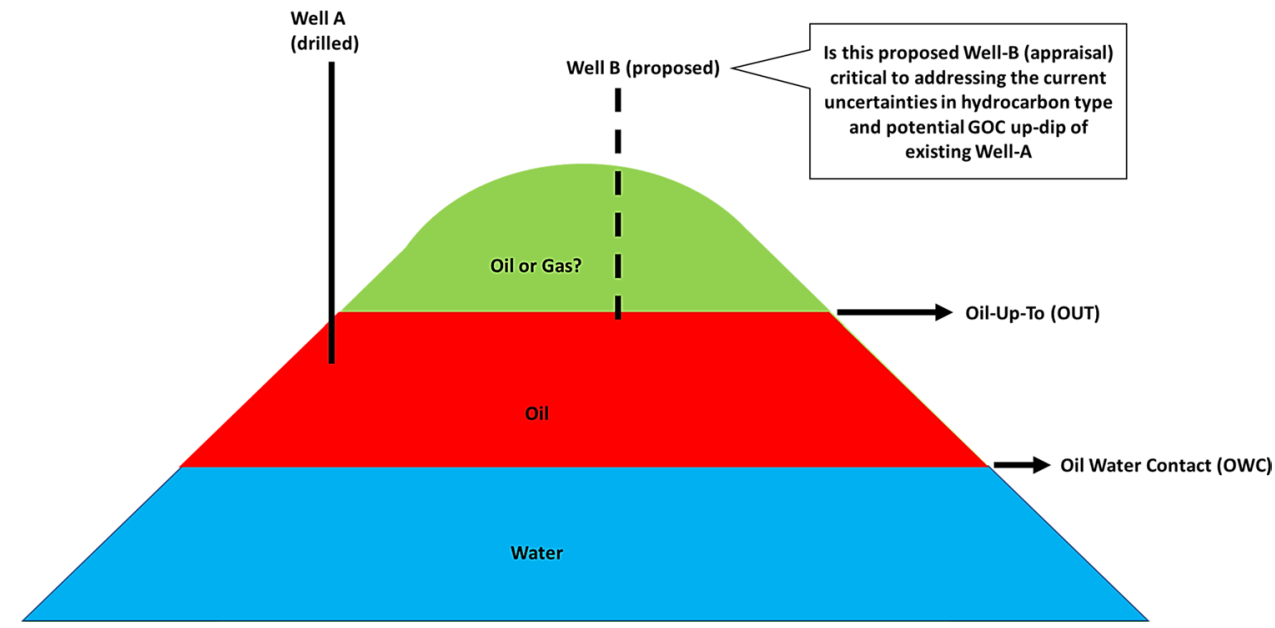


extended the concept of CGS to solving the isothermal gravity-chemical equilibrium problem $[8,5]$. In their work, an attempt to characterize saturation pressure gradients was made for different classes of fluid samples, ranging from black oil to near critical oil. Based on some evidence, they suggested the use of the derived saturation pressure gradients as rules of thumb to guide and sense-check experimental saturation pressure gradients obtained from multiple samples in the same connected system.

Høier and Whitson evaluated simple one-dimensional models of vertical compositional grading that account for gravity, chemical and thermal effects, but cautioned against the indiscriminate use of simplified models to describe initial fluid distributions [4]. The authors also noted that a thermal gradient weakens the corresponding compositional gradient. On the other hand, Pedersen and Lindeloff published a model that was premised on irreversible thermodynamics, in which compositional gradient was simulated using a vertical temperature gradient. They observed that the dampening of compositional gradient by the inclusion of a thermal gradient effect depends on the approach taken at resolving the component specific enthalpies [3].

Contrary to the general view that compositional grading depends on fluid samples and their characterization, Kiani et al. [9] reported that the augmentation of fluid characterization by splitting plus fractions of fluid composition did not have a significant impact on the compositional gradings of both hydrocarbons and non-hydrocarbons in a given system. However, it is understood that GOC prediction from CGS is sensitive to the quality and representativeness of the underlying PVT dataset.

Applying the principle of compositional grading to locate possible GOCs in some Niger-Delta reservoirs with PVT samples, Eyitayo et al. showed that compositional grading simulations offer significant potential to reduce uncertainties relating to the existence of a gas cap (or an oil column) in petroleum reservoirs [1]. However, these example applications used a combination of detailed PVT datasets and rigorous CGS. In the absence of such detailed datasets, the feasibility of applying the rigorous simulations that underpinned their work is debatable, if not impossible.

In summary, the principles of compositional gradient, the methods and models described in the foregoing and other studies, are hinged primarily on the availability of credible fluid samples. However, in the case of very limited PVT data, especially in a green field, a direct application of CGS as currently described in the literature may not be feasible. In this regard, Ahmed proposed a method to estimate possible GOCs in reservoirs with limited PVT, pending the drilling of a well to identify the fluid contact depths [10]. However, Ahmed noted that this method assumes zero compositional grading in reservoirs [10], which limits its use in thick reservoirs with compositional variation of fluids. Furthermore, against the backdrop that compositional grading is a wellknown active phenomenon over the geological history most petroleum reservoirs, the non-inclusion of this effect is an obvious shortcoming of the simple technique postulated by Ahmed.

To address the challenges presented in cases of limited PVT data, this paper develops a predictive model and practical workflow that extends the traditional applicability of CGS. It presents a new technique for estimating GOC from CGS, using a limited number of input PVT data that are readily available. As a result, the method offers a cheap and HSE-compliant means of reducing GOC uncertainties in petroleum reservoirs.

\section{Proposed method}

The present study examines the problem of estimating GOCs with limited PVT data. It offers a simplification of the compositional grading method by developing semiempirical models to estimate some of the critical inputs required for CGS. Our approach entails the following steps:

- Develop a semi-empirical model for estimating saturation pressure gradient for a given hydrocarbon sample.

- Estimate the degree of undersaturation (relative to the saturation pressure) of the hydrocarbon sample at its known sampling depth.

- Convert the resulting degree of undersaturation to its depth (column) equivalence below a possible GOC, by applying reservoir fluid gradients and saturation pressure gradients.

All the common compositional grading model assumptions, which include a continuous geological unit at steady state, are applicable [1, 3-7].

In locating a potential GOC in an equilibrated reservoir, saturation pressures of an oil sample are understood to reduce with depth, while the reservoir pressure increases with depth. Consequently, the depth at which the saturation and reservoir pressure curves coincide is a potential GOC within the system (Fig. 2). As illustrated in Fig. 2, the degree of undersaturation of oil sample increases with depth. Conversely, the undersaturation of a gas sample reduces with depth.

\section{Model development and workflow}

To solve the case of limited PVT data, we invoke the mathematical expression formulated by Høier and Whitson [4]. The said expression, reproduced in a modified form here 
Fig. 2 Graphical illustration of the principle of compositional grading $\left(P_{\text {sat }}=\right.$ saturation pressure curve, $P_{\mathrm{g}}=$ gas pressure line, $P_{\mathrm{o}}=$ oil pressure line)

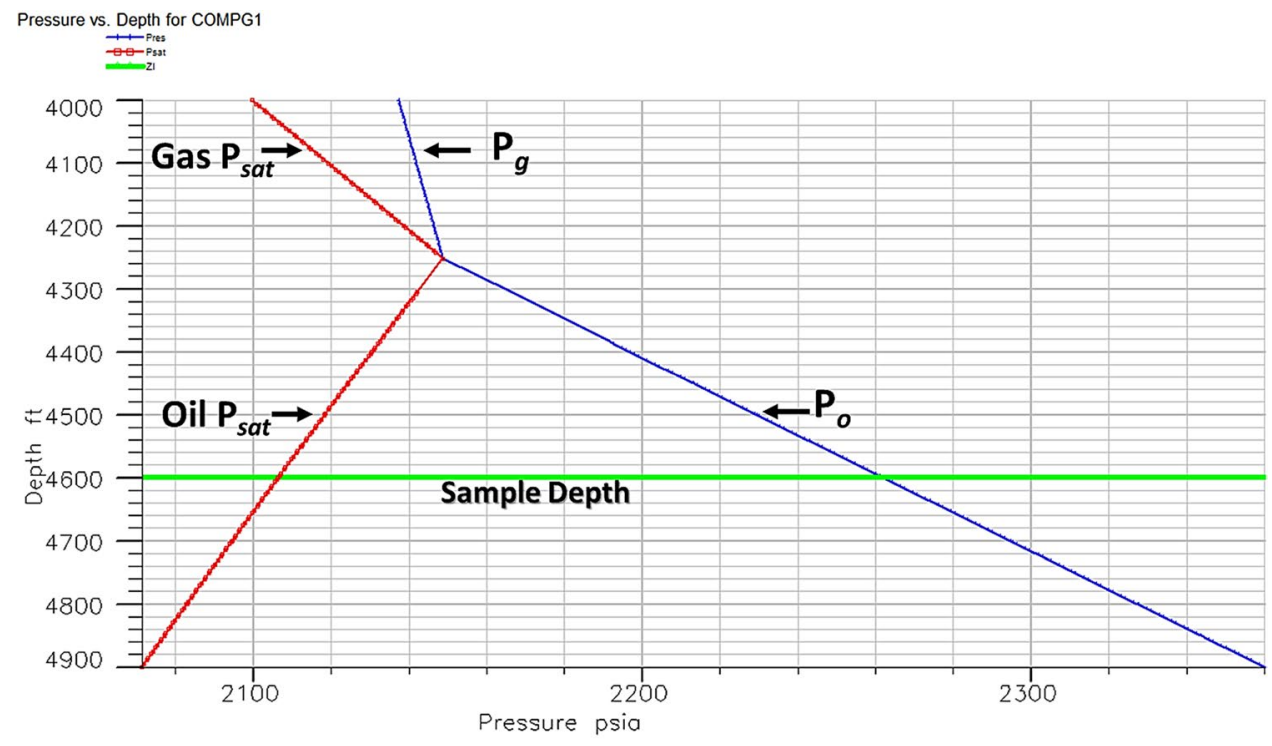

as Eq. 1, is used to locate a possible GOC as a function of some measurable thermodynamic quantities.

This current work explores the application of Eq. 1 by taking a step further in characterizing the saturation pressure gradient using a fluid property that is readily measurable, preferably at surface. In principle, the use of such cheap input data offers an opportunity to eliminate the costs and HSE exposure associated with the acquisition of subsurface fluid samples and conducting full PVT experiments.

$z_{\mathrm{GOC}}=z_{\mathrm{s}}-\left(\frac{P_{\mathrm{s}}-P_{\mathrm{bs}}}{A+\gamma}\right)$,

where $z_{\mathrm{GOC}}=\mathrm{GOC}$ depth $(\mathrm{ft}), z_{\mathrm{s}}=$ sample depth $(\mathrm{ft}), P_{\mathrm{s}}=$ reservoir pressure at sample depth (psia), $P_{\mathrm{bs}}=$ saturation (bubble-point) pressure at sample depth (psia), $A=$ absolute value of saturation pressure gradient (psi/ft) and $\gamma=$ oil pressure gradient (psi/ft).

The underlying principle in Eq. 1 is the use of appropriate pressure gradients to convert the difference (i.e., degree of undersaturation) between reservoir pressure and saturation pressure at a given sample depth to a potential GOC. This conversion is based on the fundamental assumption that the reservoir is characterized by a good vertical connectivity. This assumption is basic to all CGS techniques $[4,5]$.

For simplicity, the current work assumes that the quantities $A$ and $\gamma$ in Eq. 1 do not change for a given sample throughout the oil zone. As a physical constraint, a reservoir would be interpreted as potentially saturated if the $z_{\mathrm{GOC}}$ estimated from Eq. 1 lies between the known reservoir crest and the oil sample depth. Otherwise, it is considered that such a reservoir is unlikely to be saturated.
To give high confidence in the evaluation of GOC, two of the parameters in Eq. 1 require a closer attention and relatively higher accuracy. These parameters are the bubble-point pressure $\left(P_{\mathrm{bs}}\right)$ of the fluid at the sample depth and the saturation pressure gradient $A$. By conventional practice, $P_{\mathrm{bs}}$ and $A$ are easily obtained from PVT experiments and subsequent fluid characterization/compositional grading simulations, respectively. However, in the absence of a detailed PVT dataset, the application of Eq. 1 requires a reliable process of estimating the two unknown parameters.

To facilitate the estimation of these two important unknown parameters and hence estimate a potential GOC within the reservoir, we develop a new workflow (Fig. 3). In the next sections, we present methods for estimating the quantities $A$ and $P_{\text {bs }}$ for common oil samples.

\subsection{Correlation for estimating saturation pressure gradient}

Using samples from the North Sea, Whitson and Belery [5] characterized the saturation pressure gradients of four different crude oil types, viz. black, slightly volatile, volatile and near-critical oil (Fig. 4). For each crude class, the cumulative saturation pressure gradient was plotted against its depth relative to the GOC. Their results indicate that saturation pressure gradient generally varies from a low of $0.025 \mathrm{bar} / \mathrm{m}(0.11 \mathrm{psi} / \mathrm{ft})$ for black oil, to a high of $1 \mathrm{bar} / \mathrm{m}(4.42 \mathrm{psi} / \mathrm{ft})$ for near-critical oil in the vicinity of the GOC. Høier and Whitson [4] suggested that this range and plot could be used to sense-check experimental values of saturation pressure gradient for most oil samples. 


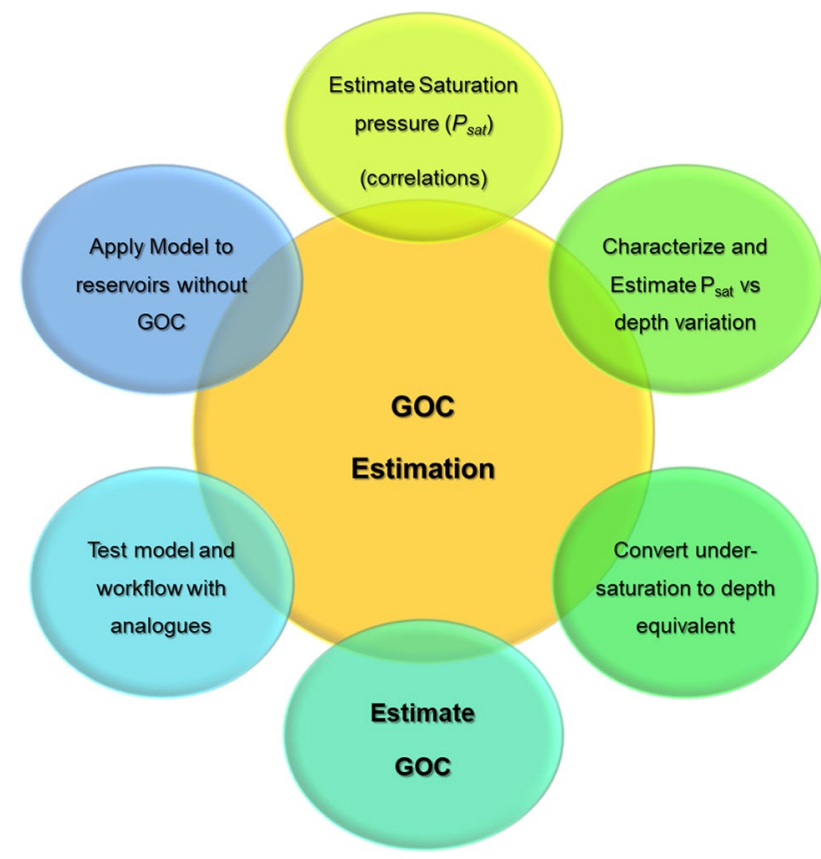

Fig. 3 Workflow for the development and application of a new model for estimating GOC in the absence of detailed PVT data

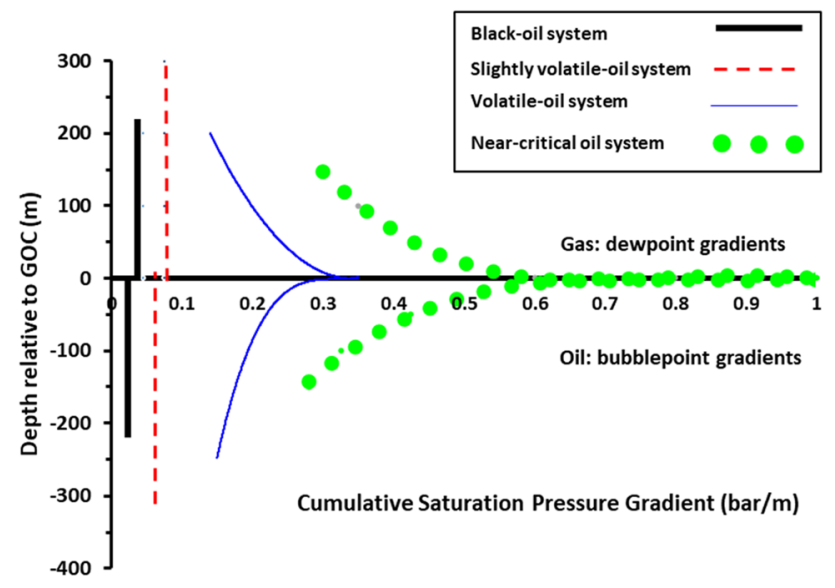

Fig. 4 Cumulative saturation pressure gradient for depths relative to GOC, modified from Whitson and Belery [5]

\subsection{New correlation for saturation pressure gradient}

A detailed process was implemented to develop a semiempirical model for estimating the quantity $A$. For reservoirs with limited PVT data, the estimation of a saturation pressure gradient involves establishing a database of saturation pressure gradients from credible and well-characterized oil samples that have detailed PVT datasets and developing a robust correlation between the quantity $A$ and a readily available surface-measurable oil property.
More than 20 oil samples, covering different terrains (onshore and offshore), oil types (black to highly volatile) and depositional environments in the Niger Delta, were examined. The available experimental PVT datasets for these samples were submitted to rigorous screening such as consistency assessment, quality checks, equationof-state (EOS) characterization, as well as agreement with independent sources such as petrophysical and pressure interpretations. At the end of rigorous screening, some $40 \%$ of the samples were found suitable for the intended application. PVTsim ${ }^{\mathrm{TM}}$, a commercial PVT simulator developed by Calsep, was used for EOS characterization and all compositional-grading simulations.

Using the selected (i.e., "good") samples, the following is a summary of the steps undertaken to generate a database of quantity $A$ subsequently used to develop the required correlation.

- Performed standard EOS characterization on the PVT dataset for each sample

- Conducted compositional-grading simulations on each sample's PVT model to predict the GOC

- Compared the GOC predicted from the CGS against logged GOC (or that from pressure analysis) in each case. Where GOC from CGS and log (or pressure analysis) differ by more than $10 \mathrm{ft}$, the characterized PVT model was tuned and CGS repeated until an acceptable GOC match was obtained (Table 1). The choice of $10 \mathrm{ft}$ as the upper limit of deviation was to account for uncertainties in petrophysical log interpretations of GOC. Such uncertainties can be attributed to several factors, including data quality, capillary effects, environmental distortions and other phenomena

- From the CGS output, the gradient of oil bubble-point curve (i.e., curve labeled "oil $P_{\text {sat }}$ " in Fig. 2) was determined as illustrated in Fig. 5. This gradient is the quantity $A$ for the sample in question. Note that in some cases (e.g., volatile oil), the oil $P_{\text {sat }}$ curve was not quite

Table 1 CGS prediction versus logged GOC for some of the source reservoirs

\begin{tabular}{lccl}
\hline Reservoir & Logged GOC (ftss) & $\begin{array}{l}\text { Simulated } \\
\text { GOC (ftss) }\end{array}$ & $\begin{array}{l}\text { Absolute } \\
\text { deviation } \\
(\mathrm{ft})\end{array}$ \\
\hline A & 10,578 & 10,575 & 3 \\
B & 7856 & 7855 & 1 \\
C & 8289 & 8295 & 6 \\
D & 8088 & 8080 & 8 \\
E & 6564 & 6560 & 4 \\
F & 5257 & 5260 & 3 \\
G & 8437 & 8429 & 8 \\
Average & & & 4.7 \\
\hline
\end{tabular}




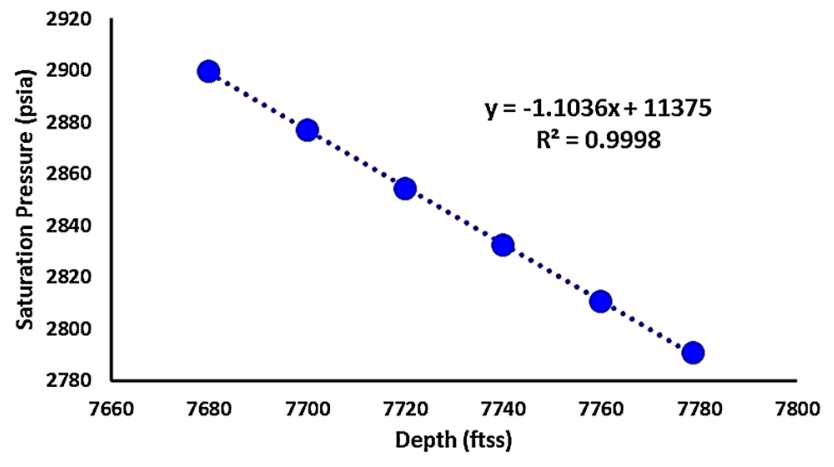

Fig. 5 Derivation of A from a plot of bubble-point pressure versus depth (below the simulated GOC)

linear (Fig. 6). This notwithstanding, an average gradient was estimated for the curve and taken to be a fair representation of the curve.

- Based on the above, a database of $A$ was established for the set of "good" samples.

- Using the above database, the most appropriate and readily available oil property that could serve as an independent variable to correlate the quantity $A$ was investigated. the identified correlating variable was established.

- Employing other credible PVT data and reservoirs (not included in the source data used to develop the above
- The most robust mathematical function relating $A$ and

correlation), blind tests were conducted on the above correlation.

As a comparison, it is re-assuring that the value $A=1.1036 \mathrm{psi} / \mathrm{ft}$ in Fig. 5 for one of the "good" Niger Delta samples is within the range $0.11-4.42 \mathrm{psi} / \mathrm{ft}$ reported by Whitson and Belery [5] for several North Sea samples. Again, it is noteworthy that Fig. 5 presents $P_{\text {sat }}$ as a function of depth and hence the negative slope $(A)$. This differs from the common approach of plotting depth versus $P_{\text {sat }}$ (e.g., Fig. 2) which, as a result, yields positive slope. Although the latter plot is generally more convenient to read (i.e., the industry appears used to having depth on the ordinate axis), we consider the former plot to be more scientifically consistent, as it correctly presents $P_{\text {sat }}$ rather than depth, as the dependent variable. This explanation is the main reason for our position that the absolute value of the quantity $A$ should be used when implementing Eq. 1 .

$A$ reasonable correlation between the new set of the "quantity $A$ " data and some surface measurable oil properties such as API gravity, viscosity and initial solution GOR $\left(R_{\mathrm{si}}\right)$ was investigated in succession. Each of these properties was treated as independent, hence, for simplicity; we did not examine their combinations/ interactions as independent variables. Due to the strict acceptance criteria imposed on the source dataset, only a limited number of source samples qualified for this exercise. Among all the various cross-plots examined, that of $A$ versus $R_{\text {si }}$ yielded the most reasonable trend

Fig. 6 An example CGS with a nonlinear oil $P_{\text {sat }}$ curve

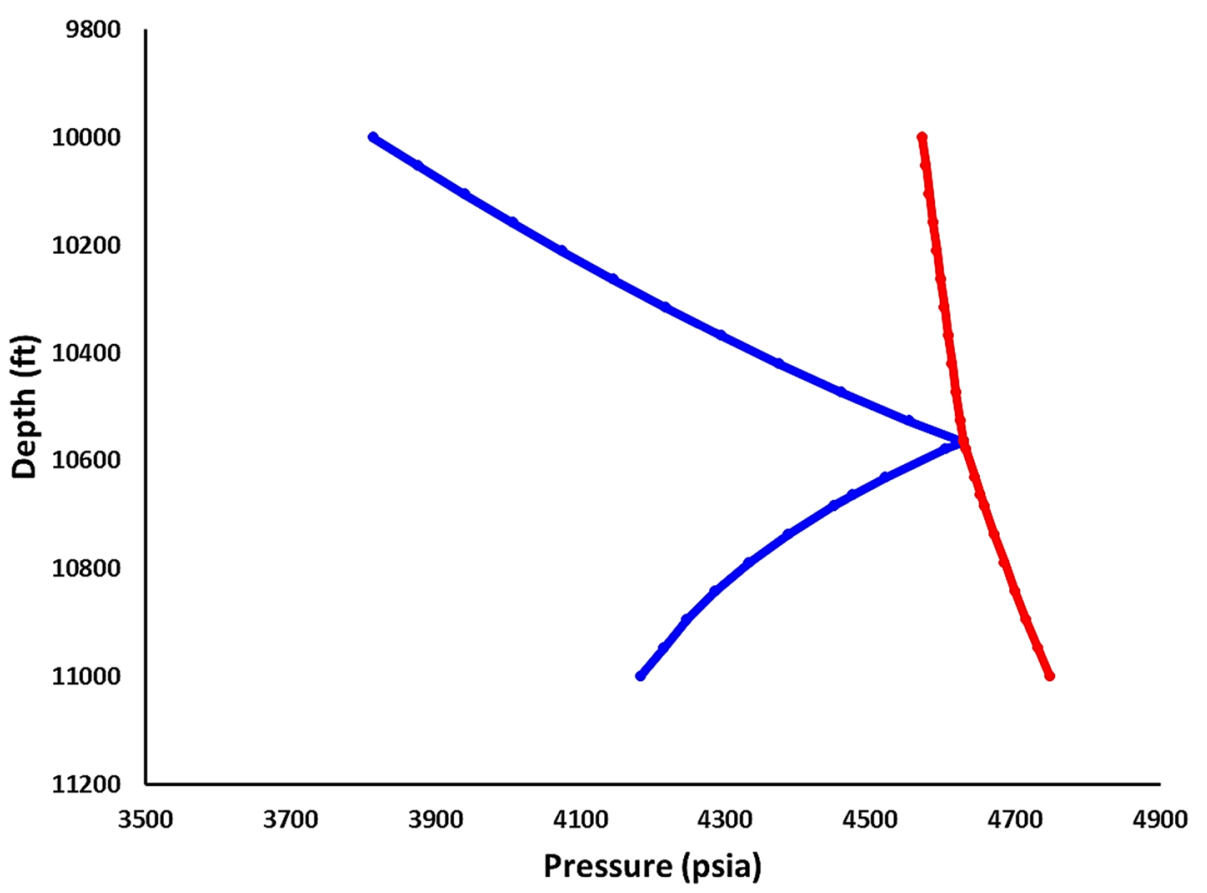




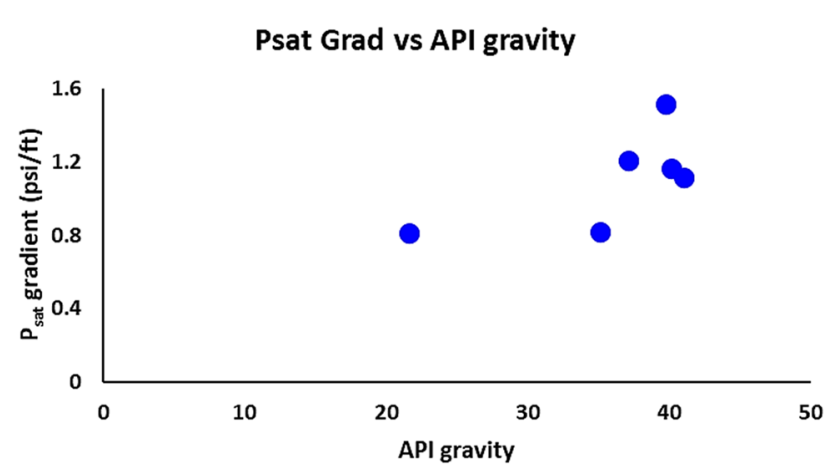

Fig. 7 A versus API data for the "good" samples

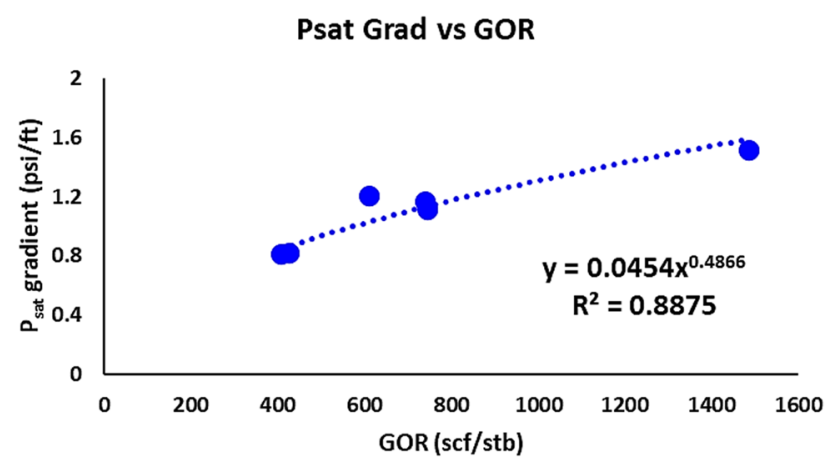

Fig. $8 A$ versus $R_{\mathrm{si}}$ data for the "good" samples, correlated using the power law function

(Figs. 7, 8). Having established that $A$ is best correlated with $R_{\text {si }}$, we went further to establish the most appropriate functional relationship between $A$ and $R_{\mathrm{si}}$ for the "good" samples in this study.

Linear, exponential and power-law functions reveal reasonable relationships between the quantities $A$ and $R_{\mathrm{si}}$, as evident in the correlation coefficients $\left(R^{2}\right)$ of 0.84 , 0.77 and 0.89 , respectively (Eqs. $2-4$ ). In addition to yielding the highest $R^{2}$, the power-law function presents the most realistic $A$ versus $R_{\text {si }}$ model (Fig. 8). To demonstrate the latter point, we consider a limiting case of $\mathrm{GOR}=0$ $\mathrm{scf} / \mathrm{stb}$. Under such a scenario, negligible compositional grading is expected and hence $A \sim 0 \mathrm{psi} / \mathrm{ft}$. Substitution of $R_{\mathrm{si}}=0$ in Eqs. 2-4 would reveal that only the power-law model (Eq. 4) satisfies this simple reality check.

Linear function: $A=0.0006 R_{\mathrm{si}}+0.6470, R^{2}=0.84$

Exponential function: $A=0.7213 e^{0.0005 R_{\text {si }}}, R^{2}=0.77$

Power function: $A=0.0454 R_{\mathrm{si}}^{0.4866}, R^{2}=0.89$

where $A$ and $R_{\mathrm{si}}$ are in psi/ft and scf/stb, respectively.
Therefore, in the absence of detailed experimental PVT dataset, the new empirical correlation (Eq. 4) provides a simple alternative to the traditional CGS method of predicting the quantity $A$ and hence potential GOC. Among other advantages, the key merits of this correlation include: (1) It allows an estimation of the quantity $A$ from a readily available surface-measured fluid property (GOR); (2) it does not require detailed and costly PVT dataset; and (3) it is computationally cheap.

\subsection{Selection of correlation for estimating saturation (bubble point) pressure}

According to Eq. 1, a credible knowledge of the bubblepoint pressure $\left(P_{\mathrm{b}}\right)$ at a reference depth is required to evaluate a potential GOC in a reservoir with limited PVT dataset. In the absence of experimental $P_{\mathrm{b}}$ measurement at the depth of interest, empirical correlations are available to address the gap. Because the development of a $P_{\mathrm{b}}$ correlation is outside the scope of this paper, we focus on the selection of an appropriate correlation for the "good" samples considered in the current work. The following criteria were considered to narrow the candidate correlations.

- Correlations developed from Niger Delta samples

- Correlations of good accuracy. For this purpose, we limit our search to correlations that have reported average absolute relative error (AARE) below $10 \%$.

- Correlations must have a wide range of applicability.

To keep the problem tractable, five Niger Delta correlations were tested [11-13]. Table 1 lists these correlations and their AARE as reported by the original authors. Although not premised on Niger Delta crudes as applicable to others, the popular Standing's correlation [14] was included for comparison. The last column in Table 1 presents the performances of these correlations when applied to all the "good" samples covered in the present study (Table 2).

Based on the foregoing evaluations, we found the Okoduwa and Ikiensikimama [12] model (for the range $35<\mathrm{API} \leq 45$ ) as the most accurate for the samples examined herein. However, because this correlation is limited to a certain API range, we have selected the Ikiensikimama and Ogboja [11] model, which exhibits comparable accuracy, yet with a much wider range of applicability. For completeness, the Okoduwa and Ikiensikimama [12] correlation is reproduced here as Eqs. 5-8.

$$
Q=\frac{R_{\mathrm{si}}}{x_{1}\left(R_{\mathrm{si}} / x_{1}+x_{2} \gamma_{\mathrm{o}} / s_{\mathrm{o}}\right)},
$$


Table 2 Bubble-point pressure correlations considered in this study

\begin{tabular}{|c|c|c|c|}
\hline Correlation & Data source & $\begin{array}{l}\text { AARE (\%) (reported by } \\
\text { original authors) }\end{array}$ & $\begin{array}{l}\text { AARE (\%) } \\
\text { (this study) }\end{array}$ \\
\hline Oloruntoba and Onyekonwu [13] & Niger-Delta crudes & 3.74 & 28.09 \\
\hline Ikiensikimama and Ogboja [11] & “ & 8.19 & 7.12 \\
\hline $\begin{array}{l}\text { Okoduwa and Ikiensikimama [12] } \\
21<\mathrm{API} \leq 26\end{array}$ & “ & 5.61 & 21.89 \\
\hline $\begin{array}{l}\text { Okoduwa and Ikiensikimama [12] } \\
26<\mathrm{API} \leq 35\end{array}$ & “ & 6.74 & 81.13 \\
\hline $\begin{array}{l}\text { Okoduwa and Ikiensikimama [12] } \\
35<\mathrm{API} \leq 45\end{array}$ & “ & 8.08 & 6.26 \\
\hline Standing [14] & Californian crudes & 11.19 & 14.85 \\
\hline
\end{tabular}

$P_{\mathrm{bs}}=\frac{P_{\mathrm{b}}^{*}\left(T+x_{10}\right)}{\gamma_{\mathrm{g}}}$

not included in the database used to construct the new semiempirical model (Eq. 4). The former set of eight reservoirs was reserved strictly for validation tests.

The class-I consists of saturated reservoirs with well penetrations, which have confirmed their GOC depths, as established by petrophysical logs and/or static pressure datasets. The class-II examples are proven undersaturated reservoirs as deduced from petrophysical logs, static pressures and/or production history.

where $\gamma_{\mathrm{o}}=$ oil specific gravity (water $\left.=1\right), \gamma_{\text {API }}=$ stocktank oil gravity $\left({ }^{0} \mathrm{API}\right), T=$ reservoir temperature $\left({ }^{\circ} \mathrm{F}\right)$ and $\gamma_{\mathrm{g}}=$ surface gas gravity (air $=1$ ). The constants are $x_{1}=336.0064009, x_{2}=6.7063984, x_{3}=47.57094772$, $x_{4}=0.677706662, x_{5}=1.530935619, x_{6}=0.243181338$, $x_{7}=-2.316548789, x_{8}=10.60657909, x_{9}=1.518030465$ and $x_{10}=635.4152349$.

\section{Validation of proposed model and workflow}

To validate the new models and the proposed workflow for estimating potential GOC in reservoirs with limited PVT dataset that precludes rigorous CGS, we consider samples from some oil reservoirs in the Niger Delta, both onshore and offshore. The examples include known saturated and undersaturated reservoirs, which are identified as classes I and II, respectively. It is worthy of note that the set of example reservoirs employed for the validation tests was

\subsection{Class-I examples}

The class-I reservoirs and their basic data are provided in Table 3. As discussed earlier, the $P_{\mathrm{b}}$ values at the sampling depths were obtained from the correlation of Ikiensikimama and Ogboja [11], while the corresponding quantity $A$ was estimated from Eq. 4 . With the relevant input data, it was straightforward to calculate the corresponding GOC depths from Eq. 1. The relevant results are given in Table 4.

A clear observation from Table 4 is the good agreement between the predicted and actual GOC depths for the five reservoirs investigated. The differences between the predicted and actual GOCs are characterized by an arithmetic mean and standard deviation of 13 and $10 \mathrm{ft}$, respectively. Given the uncertainties often associated with GOC measurements (Eyitayo et al. [1]), an average deviation of $13 \mathrm{ft}$ suggests that the proposed simple method of predicting GOC is promising for practical applications.
Table 3 Class-I reservoirs and their input data

\begin{tabular}{lllllll}
\hline Reservoir & $\begin{array}{l}\text { Sample } \\
\text { depth } \\
\text { (ftss) }\end{array}$ & $\begin{array}{l}\text { Pressure at sam- } \\
\text { ple depth (psia) }\end{array}$ & $\begin{array}{l}\text { Temperature at } \\
\text { sample depth }\left({ }^{\circ} \mathrm{F}\right)\end{array}$ & $\begin{array}{l}\text { Reservoir } \\
\text { crest (ftss) }\end{array}$ & $\begin{array}{l}R_{\mathrm{si}} \text { (scf/stb) } \\
\text { Oil gradi- } \\
\text { ent, } \gamma \text { (psi/ } \\
\mathrm{ft})\end{array}$ \\
\hline A_55 & 5436 & 2618 & 162 & 5100 & 428 & 0.32 \\
M_84 & 7904 & 3430 & 180 & 7728 & 641 & 0.32 \\
D3.1 & 6842 & 2950 & 140 & 6720 & 306 & 0.34 \\
1-A & 9840 & 4295 & 183 & 9514 & 1499 & 0.31 \\
BM-3 & 7396 & 3202 & 166 & 7270 & 699 & 0.30 \\
\hline
\end{tabular}


Another important insight from Table 4 is the consistency of our model at predicting deeper GOCs than the reference actual measurements. From the standpoint of reservoir characterization and evaluation, this conservative trend is appropriate because it highlights potential risks to oil in-place volumes, recoveries and investments. More important, this trend suggests that the predictions from the proposed model would generally provide the upper limit of the likelihood of an oil reservoir being saturated, and the deepest GOC that can potentially be encountered in such a reservoir. As a result, the predicted GOC (i.e., deeper) is expected to return lower bound of the volume of oil in-place, and upper bound of potential free gas in-place in a typical reservoir. Philosophically, the foregoing outcome is helpful for development planning and subsequent reservoir management.

\subsection{Class-II examples}

Table 5 presents the class-II reservoirs and their basic data. The same procedure described for the class-I reservoirs was used. The relevant results for the reservoirs in this class are summarized in Table 5 . For the eight reservoirs used as examples in this study, the results presented in Tables 3, 4, 5 and 6 confirm the robustness of the proposed model and workflow for assessing potential GOC in reservoirs with limited PVT dataset. In addition, these results provide independent authentication of the Ikiensikimama and Ogboja [11] correlation for estimating bubble-point pressures, especially for Niger Delta oil systems.

Although we have successfully tested the proposed model and correlation in this study, it is worth emphasizing that our current work is more appropriate for assessing whether an oil reservoir is likely to be saturated or undersaturated, especially when such reservoir is characterized by limited PVT dataset. Therefore, given the complexities of typical reservoirs, it needs to be re-emphasized that the proposed workflow does not seek to provide a perfect prediction of GOC, but rather a reliable indicator of the presence or otherwise of a saturated reservoir given limited PVT data. This notwithstanding, under certain circumstances, the results from the application of the proposed

Table 4 Summary of results for the class-I reservoirs

\begin{tabular}{|c|c|c|c|c|c|c|}
\hline \multirow[t]{2}{*}{ Reservoir } & \multirow[t]{2}{*}{$A(\mathrm{psi} / \mathrm{ft})$} & \multicolumn{2}{|c|}{$\begin{array}{l}P_{\mathrm{b}} \text { at sample } \\
\text { depth (psia) }\end{array}$} & \multicolumn{2}{|l|}{ GOC (ftss) } & \multirow[t]{2}{*}{ Remark } \\
\hline & & Predicted & Actual & Predicted & Actual & \\
\hline A_55 & 0.89 & 2421 & 2382 & 5274 & 5257 & \multirow{5}{*}{$\begin{array}{l}\text { Good } P_{\mathrm{b}} \text { and GOC predictions. Predicted and actual } P_{b} \mathrm{~s} \text { are within } 3 \% \text {, } \\
\text { confirming robustness of recommended correlation, i.e., Ikiensikimama } \\
\text { and Ogboja [11]. Predicted and actual GOCs have mean deviation of } 13 \mathrm{ft} \text {, } \\
\text { typical uncertainty range }\end{array}$} \\
\hline M_84 & 1.11 & 3325 & 3223 & 7830 & 7826 & \\
\hline D3.1 & 0.75 & 2941 & 2888 & 6834 & 6825 & \\
\hline $1-A$ & 1.72 & 4110 & 4070 & 9749 & 9742 & \\
\hline BM-3 & 1.16 & 3181 & 3169 & 7382 & 7352 & \\
\hline
\end{tabular}

Table 5 Class-II reservoirs and their input data

\begin{tabular}{lllllll}
\hline Reservoir & $\begin{array}{l}\text { Sample } \\
\text { depth (ftss) }\end{array}$ & $\begin{array}{l}\text { Pressure at sam- } \\
\text { ple depth (psia) }\end{array}$ & $\begin{array}{l}\text { Temperature at } \\
\text { sample depth }\left({ }^{\circ} \mathrm{F}\right)\end{array}$ & $\begin{array}{l}\text { Reservoir } \\
\text { crest (ftss) }\end{array}$ & $\begin{array}{l}R_{\mathrm{si}} \text { (scf/stb) } \\
\text { Oil gradi- } \\
\text { ent, } \gamma \text { (psi/ } \\
\mathrm{ft})\end{array}$ \\
\hline $3 \_4$ & 10,260 & 4806 & 156 & 10,180 & 502 & 0.32 \\
$2 \_1$ & 11,689 & 5152 & 210 & 11,592 & 844 & 0.32 \\
$3 \_1$ & 11,964 & 5185 & 215 & 11,876 & 631 & 0.32 \\
\hline
\end{tabular}

Table 6 Summary of results for the class-II reservoirs

\begin{tabular}{|c|c|c|c|c|c|c|}
\hline \multirow[t]{2}{*}{ Reservoir } & \multirow[t]{2}{*}{$A(\mathrm{psi} / \mathrm{ft})$} & \multicolumn{2}{|c|}{$\begin{array}{l}P_{\mathrm{b}} \text { at sample depth } \\
\text { (psia) }\end{array}$} & \multicolumn{2}{|l|}{ GOC (ftss) } & \multirow[t]{2}{*}{ Remark } \\
\hline & & Predicted & Actual & Predicted & Actual & \\
\hline 3_4 & 0.97 & 1801 & 1775 & 7936 (< crest) & Undersaturated & \multirow{3}{*}{$\begin{array}{l}\text { Predicted and actual } P_{\mathrm{b}} \text { are consistent. Predicted GOCs are } \\
\text { shallower than the known reservoir crests; hence, the } \\
\text { model predicts undersaturated reservoirs. These predic- } \\
\text { tions are consistent with the actual data }\end{array}$} \\
\hline $2 \_1$ & 1.28 & 2695 & 2634 & 10,148 (<crest) & Undersaturated & \\
\hline 3_1 & 1.10 & 2463 & 2445 & 10,042 (< crest) & Undersaturated & \\
\hline
\end{tabular}


method may be used to complement other methods of predicting GOC.

\section{Conclusion}

Leveraging on the concept of compositional grading as the driver of GOC over a geologic timescale, this paper has developed and tested a new model and workflow for evaluating the potential existence of $\mathrm{GOC}$ in oil reservoirs. The new method provides a systematic integration of a new predictive saturation gradient model and a suitable bubble-point pressure model to estimate the degree of undersaturation of an oil sample at any point in the reservoir. Compared to the existing methods, the new method offers simplicity, cost efficiency (both operational and computational expenses) and minimal HSE exposure.

Employing credible PVT datasets and rigorous CGS for known black and volatile oil reservoirs, a new semi-empirical model has been developed for estimating saturation pressure gradient from GOR, which is a readily measurable fluid property. As part of this work, screening tests performed on some empirical models for estimating bubblepoint pressure found the correlation by Ikiensikimama and Ogboja [11] as most robust for the Niger Delta field examples considered. Validation tests conducted on the proposed model and workflow confirmed their robustness for assessing potential saturation or undersaturation, as well as a likely GOC depth in oil reservoirs characterized by limited PVT dataset. While not accurately determining the depth of the GOC, the proposed model reduces the associated uncertainties by estimating a GOC depth in a hydraulically continuous reservoir which, when compared to the structural crest of same reservoir, suggests the likelihood (or not) of a gas cap.

Improvements to the proposed model can be explored by taking advantage of more extensive datasets, including the Niger Delta and other basins. This may warrant focusing on developing specific models for predicting saturation pressure gradients for each of black oil, volatile oil and other oil types, either as a function of basins or basin independent.

In principle, there is a scope to extend this work to gas samples (i.e., reservoirs encountered in gas-down-to situations). Additionally, we speculate that the applicability of this work may be extended to facilitate a simple tracking of GOC advancement for the management of producing oil reservoirs. The maturation of these additional scopes is considered a research worth undertaking.

Acknowledgements The authors are grateful to Calsep A/S for providing a trial license of the commercial PVT simulator $\left(P V T \operatorname{sim}^{\mathrm{TM}}\right)$ utilized in this study.

\section{SN Applied Sciences}

\section{Compliance with ethical standards}

Conflict of interest On behalf of all authors, the corresponding author states that there is no conflict of interest.

\section{References}

1. Eyitayo S, Lawal K, Ukaonu C, Ovuru M, Sanyaolu A, Otubanjo M, Matemilola S (2017) Using compositional-grading simulations to assess gas-oil contacts: practical cases from the Niger Delta. SPE paper 189089, presented at SPE Nigeria annual international conference and exhibition, $31 \mathrm{Jul}-2$ Aug, Lagos. https://doi. org/10.2118/189089-MS

2. Hussein H, Mahgoub IS (2005) Methodology of investigating the compositional gradient within the hydrocarbon column. SPE paper 95760 , presented at SPE annual technical conference and exhibition, 9-12 Oct, Dallas. https://doi.org/10.2118/95760-MS

3. Pedersen KS, Lindeloff N (2003) Simulations of compositional gradients in hydrocarbon reservoirs under the influence of a temperature gradient. SPE paper 84364 , presented at SPE annual technical conference and exhibition, 5-8 Oct, Denver. https://doi. org/10.2118/84364-MS

4. Høier L, Whitson CH (2000) Compositional grading-theory and practice. SPE paper 63085, presented at SPE annual technical conference and exhibition, 1-4 Oct, Dallas. https://doi. org/10.2118/63085-MS

5. Whitson C, Belery P (1994) Compositional gradients in petroleum reservoirs. SPE paper 28000, presented at University of Tulsa centennial petroleum engineering symposium, 29-31 Aug, Tulsa. https://doi.org/10.2118/28000-MS

6. Schulte A (1980) Compositional variations within a hydrocarbon column due to gravity. SPE paper 9235 , presented at SPE annual technical conference and exhibition, 21-24 Sept, Dallas. https:// doi.org/10.2118/9235-MS

7. Montel F, Gouel P (1985) Prediction of compositional grading in a reservoir fluid column. SPE paper 14410, presented at SPE annual technical conference and exhibition, 22-26 Sept, Las Vegas. https ://doi.org/10.2118/14410-MS

8. Belery P, da Silva FV (1990) Gravity and thermal diffusion in hydrocarbon reservoirs. Copenhagen: paper presented at the 1990 Chalk Research Program, 11-12 June

9. Kiani M, Osfouri S, Azin R, Dehghani SA (2016) Impact of fluid characterization on compositional gradient in a volatile oil reservoir. $J$ Pet Explor Prod Technol 6:835-844

10. Ahmed T (2007) Equations of states and PVT analysis. Gulf Publishing Co., Houston, pp 49-50

11. Ikiensikimama SS, Ogboja O (2009) New bubble point pressure empirical PVT correlation. SPE paper 128893, presented at SPE Nigeria annual international conference and exhibition, 3-5 Aug, Lagos. https://doi.org/10.2118/128893-MS

12. Okoduwa IG, Ikiensikimama SS (2010) Bubble point pressure correlations for Niger Delta crude oils. SPE paper 136968, presented at SPE Nigeria annual international conference and exhibition, 31 Jul-7 Aug, Tinapa—Calabar. https://doi.org/10.2118/136968-MS

13. Oloruntoba FM, Onyekonwu MO (2016) Empirical prediction of bubble point pressure and solution gas oil ratio for Niger Delta. Int J Sci Eng Res 7(6):520-530

14. Standing MB (1947) A pressure-volume-temperature correlation for mixtures of California oils and gases. API-47-275, Drill. Prod. Practice, API

Publisher's Note Springer Nature remains neutral with regard to jurisdictional claims in published maps and institutional affiliations. 